\title{
Я. Д. Коган ${ }^{1}$, Н. В. Богданова ${ }^{2}$
}

${ }^{1-A R}$ Materials Solution, Inc.

(Тарзана, Калифорния, США)

${ }^{2-}$ Государственный университет морского и речного флота имени адмирала С.О. Макарова

(Санкт-Петербург, Россия)

\section{МАТЕРИАЛЫ И ТЕХНОЛОГИИ ФОРМИРОВАНИЯ МЕХАНИЧЕСКИХ СОЕДИНЕНИЙ МЕТОДОМ ХОЛОДНОЙ ПЛАСТИЧЕСКОЙ ДЕФОРМАЦИИ}

Дата поступления 19.10.2017

Решение о публикации 26.10.2017

\section{Аннотация:}

Постановка задачи. Выбор материалов и технологии изготовления неразъемных механических соединений трубопроводов (фитинга и трубы), формируемых методом холодной пластической деформации.

Метод. Теоретический анализ выбора материалов контактирующих пар на основе упругого последействия материалов трубы и фитинга. Упругое последействие материала трубы должно превосходить упругое последействие материала фитинга.

Результаты. Приведены рекомендации по материалам неразъемных соединений, формируемых при различных методах пластической деформации.

Ключевье слова: неразъемные соединения, радиальная пластическая деформация, упругое последствие, рекомендуемые материалы

UDC 66.083 .2

\section{J. D. Kogan' ${ }^{1}$, N. V. Bogdanova ${ }^{2}$}

${ }^{1-}$ AR Materials Solution, Inc.

(Tarzana, California, United States)

${ }^{2-}$ Admiral Makarov State University of Maritime and Inland Shipping

(St. Petersburg, Russian Federation)

MATERIALS AND TECHNOLOGY FOR FABRICATING MECHANICAL CONNECTORS BY COLD PLASTIC DEFORMATION

Of the date of receipt 19.10.2017

Of the decision to publish 26.10.2017 
Abstract:

Formulation of the problem. Choice of materials and technologies for fabrication mechanical attached fittings (MAF) performed by cold plastic deformation.

Method. Theoretical analysis based on mechanical properties fitting and tubing materials. Springback tubing materials shall exceed springback tubing materials.

Results. Describes recommendations for materials of contact connections, formed with various methods of plastic deformation.

Keywords: non-detachable contact connections, radial plastic deformation, springback fitting and tubing materials, contentfeatured materials

\section{Введение}

В статье анализируются материалы и современные технологии производства неразъемных механических соединений методом холодной пластической деформации.

Формирование механических соединений методом холодной пластической деформации является альтернативным методом традиционным технологиям соединения различных материалов и компонентов, производимых путем сварки, пайки и нарезанием резьбы.

Анализируемые типы соединений, получившие известность как MAFсоединения (mechanically attached fitting), широко применяются в авиации, судостроении, производстве гидравлических систем, линий высоковольтных передач и заземлений.

\section{Типы и методы изготовления механических соединений (MAF)}

Следующие типы механических соединений, формируемые методом холодной пластической деформации, получили наибольшее распространение:

- радиально сжатые соединения;

- аксиально сжатые соединения;

- радиально - аксиально сжатые соединения.

Рассмотренные механические соединения образуются путем холодной пластической деформации трубы и фитинга, которые работают в непосредственном контакте. Обычно используется стандартная технология, которая основана на деформации контактирующих пар в специальных пресс-формах, в которых размеры компонентов изменяются под действием сжимающей нагрузки [1 - 6].

Приведенные ниже методы пластического деформирования для изготовления механических соединений являются наиболее распространенными: 


\section{Радиальное сжатие}

Механические соединения высокого качества производятся методом радиального обжатия, которое приводит к радиальной деформации определенной величины (радиально сжатые MAF соединения).

Эта технологическая схема используется для производства неразъемных соединений трубопроводов. Радиальная деформация достигается одновременным обжатием фитинга и трубы по всей длине окружности $\left(360^{\circ}\right)$.

Контактное взаимодействие поверхностей фитинга и трубы обеспечивает высокую адгезию (сцепление) между ними и гарантирует отсутствие течи в процессе эксплуатации систем трубопроводов (рис. 1).

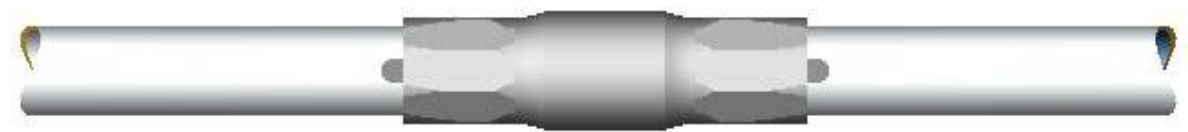

Рис. 1. Механическое соединение, полученное радиальным сжатием

\section{Осевое сжатие}

Пластическая деформация достигается путем перемещения специального V-образного кольца (наконечника) по поверхности фитинга в осевом направлении, что создает радиальные сжимающие напряжения во взаимодействующих зонах фитинга и трубопровода, и таким образом обеспечивает необходимую герметичность контакта (аксиально сжатые MAF) (рис. 2).

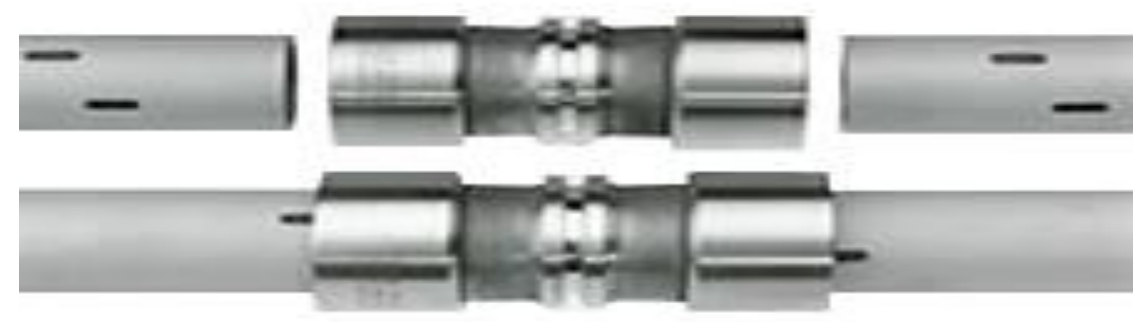

Рис. 2. Механическое соединение, полученное аксиальным сжатием

Радиально-осевое сжатие (аксиальное обжатие концевого фитинга с раструбом торцевой части трубы)

Эта технология используется для изготовления фитингов, установленных на конце трубы. В этом случае пластическая деформация достигается за счет осевого перемещения фитинга и трубы в специальной пресс-форме, что делает возможным образование сжимающих радиальных 
напряжений в фитинге и в концевой части трубы. Расширенный конец трубы (раструб) обеспечивает высокую герметичность соединения (рис. 3).

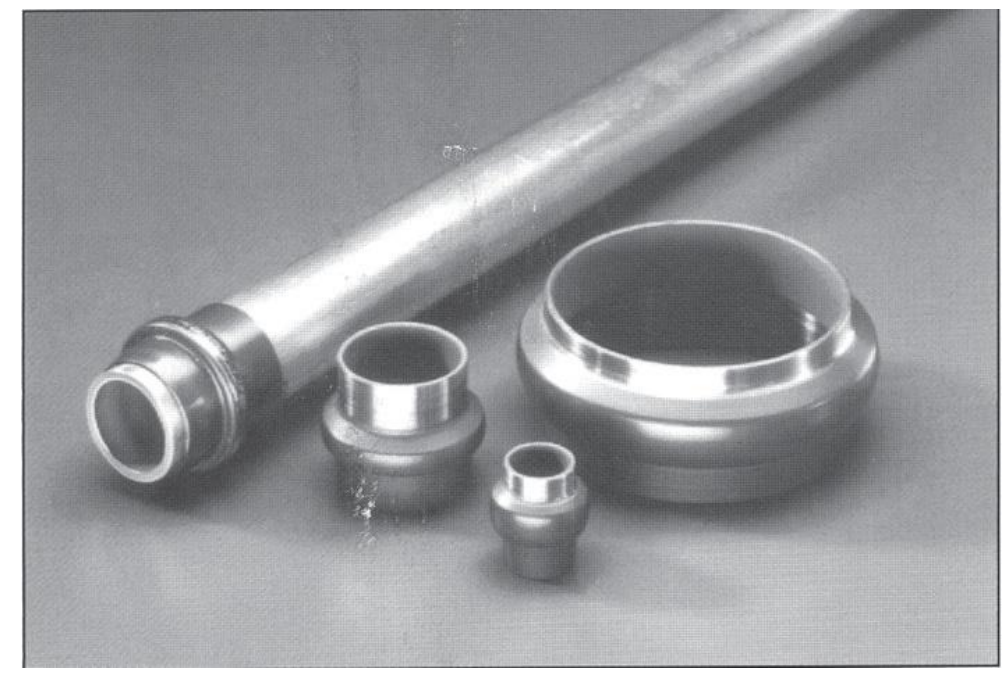

Рис. 3. Механическое соединение, полученное радиально-аксиальным сжатием

Рассмотренные механические соединения гарантируют воздухонепроницаемое состояние в зонах контакта, обеспечивая тем самым высокую производительность соединений в гидравлических трубах под высоким давлением (до 4000 - 5000 psi).

Эта технология используется в производстве новых трубопроводов, а также для ремонта эксплуатационных линий трубопроводов.

Экономическая эффективность соединений обусловлена простотой их монтажа, осмотра, а также возможностью использования труб из различных металлических материалов.

Согласно Subtek [2], производительность рассматриваемой технологии более, чем в два раза выше по сравнению с методом сварки. Кроме того, трудоемкость изготовления таких соединений сокращается на $50 \%$.

\section{Теоретические основы формирования механических соединений}

Технология основана на различии механических свойств (упругое последействие) материалов, используемых в контактирующих деталях.

Степень упругого последействия фитинга и трубы, которое возникает после снятия сжимающей нагрузки отвечает за формирование плотного стыка металл-металл. Упругое последействие трубы должно быть больше, чем упругое последействие фитинга в области произведенного обжатия.

Рис. 4 показывает образование механического соединения под действием радиальной сжимающей нагрузки, и упругие последействия контактирующих материалов когда упругое последействие трубы выше упругого последействия фитинга. Поперечные сечения фитинга - трубы представлены на разных этапах формирования механического соединения. 

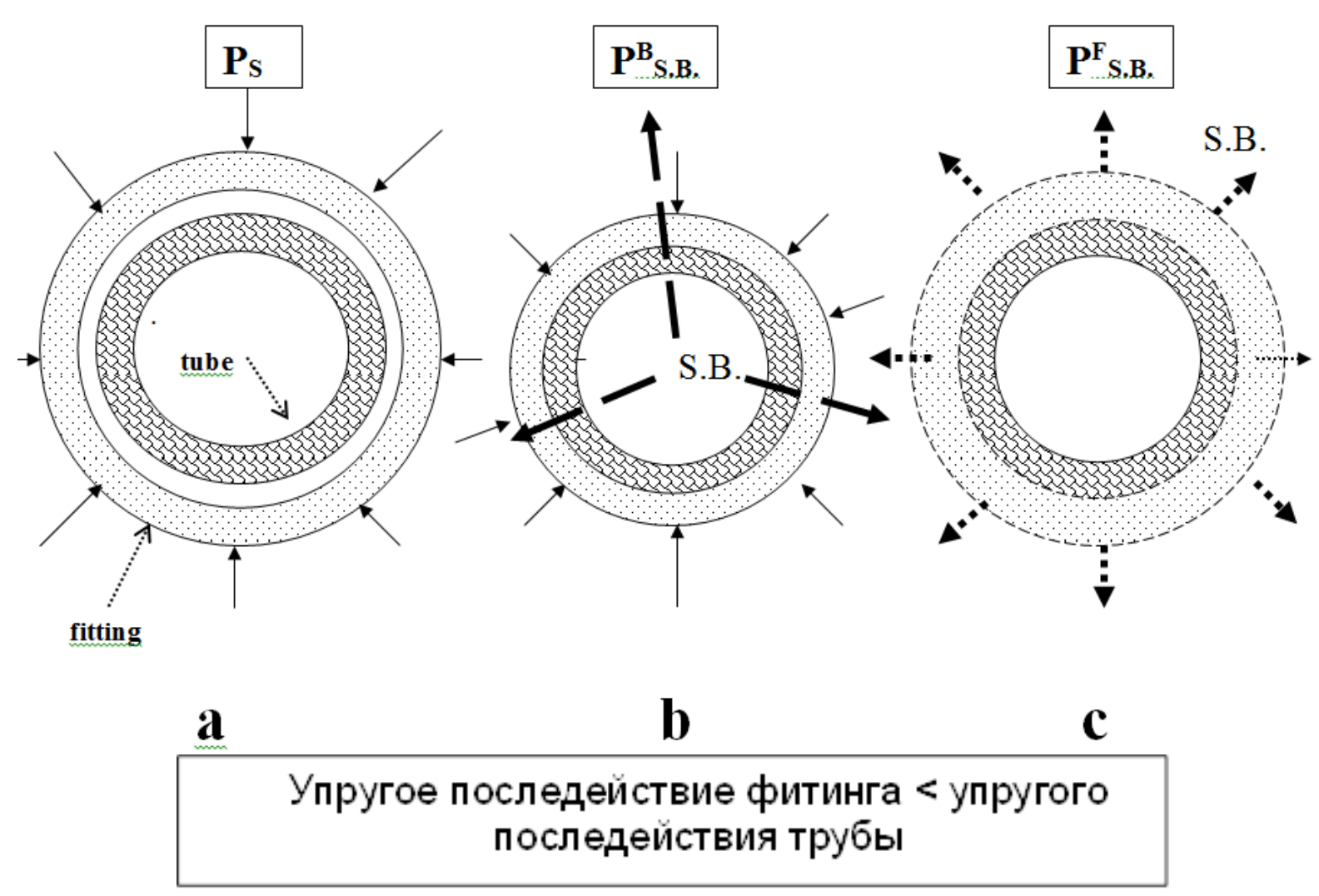

Рис. 4. Взаимосвязь упругого последействия трубы и фитинга

Позиция "a" показывает начальную стадию деформации, в которой фитинг и труба не имеют прямого контакта, и сжимающая нагрузка $\left(\mathrm{P}_{\mathrm{S}}\right)$ равномерно распределена по внешней поверхности фитинга.

Деформация фитинга, которая сопровождается его сжатием, приводит к непосредственному контакту внутреннего диаметра фитинга и внешнего диаметра трубы. Дальнейшее действие сжимающей нагрузки вызывает деформацию трубы. В этом случае сопротивление сжимаемых материалов действию внешней нагрузки растет и возникает эффект упругого последействия материалов фитинга и трубы ( $\mathrm{P}^{\mathrm{B}}$ S.в.). Рисунок 4 (позиция "б") показывает позицию контактирующей пары на этой стадии деформации.

После того, как действие внешней сжимающей нагрузки прекращается упругое последействие внутренних напряжений материалов фитинга и трубы приводит к обратному перемещению деформированных слоев деталей, которое сопровождается расширением фитинга и трубы.

Когда упругое последействие материала фитинга ниже упругого последействия материала трубы, возникает прямой контакт внутренней поверхности фитинга и внешней поверхности трубы, что приводит к высокой адгезии (сцеплению) контактирующих поверхностей (положение "c"). 
Изменение размеров в результате упругого последействия может быть определено согласно методу, представленному в работе [7]. Степень упругого последствия пропорциональна отношению YS / (t•E), где YS предел прочности, E - модуль упругости и $\mathrm{t}$ - толщина стенки детали [7].

Для контактирующих деталей упругое последействие является функцией предела величин предела текучести и модуля упругости материалов, используемых в трубе и фитинге. При этом, степень уплотнения определяется, по формуле (1):

$$
\begin{aligned}
& I=\frac{Y S_{t}}{Y S_{f}} \cdot \frac{E_{f}}{E_{t}} \\
& \text { Где: } \quad \mathrm{I}-\quad \text { степень уплотнения; } \\
& \quad Y S_{t}-\text { предел текучести материала трубы; } \\
& Y S_{f}-\text { предел текучести материала фитинга; } \\
& \mathrm{E}_{\mathrm{f}}-\text { модуль упругости материала фитинга; } \\
& \mathrm{E}_{\mathrm{t}}-\text { модуль упругости материала трубы }
\end{aligned}
$$

\section{Рекомендуемые материалы для формирования механических соединений}

Для производства фитингов рекомендуется использовать нержавеющую сталь (преимущественно аустенитного класса), алюминиевые сплавы, технически чистый титан, титановые сплавы с $6 \%$ алюминия и 4\% ванадия.

Из алюминиевых сплавов, главным образом, используется сплав АД 33 по ГОСТ 4784-97 (6061-T6, AMS 4127J и AMS 4150L ), из аустенитных нержавеющих сталей используется сталь 03Х17Н14М3 по ГОСТ 5632-72 (21-6-9 AMS 5595 и 316L, AMS 5524 и AMS 5507), из дисперсионно твердеющих сталей - - сталь 07Х16Н4Д4Б, ГОСТ 5632-72 (17-4PH, AMS 5622 и AMS 5643).

Химический состав материалов, а также их термообработка должны обеспечить максимальную пластичность материала при холодной деформации; поэтому, в соответствии со стандартом SAE AS4459 (4) для материала фитингов введен контроль диапазона текучести при растяжении, а для технически чистого титана - содержания водорода. 
Для алюминиевого сплава АД 33 (ГОСТ 4784-97) значение предела текучести при растяжении должно находиться в диапазоне от 193 до 227 МПа, что достигается при применении дополнительной термической обработки (перестаривание).

Аустенитные нержавеющие стали должны быть в отожженном состоянии и их предел текучести не должен превышать 448 МПа для 21-69SS и 310 МПА для стали 316L.

Предел текучести технически чистого титана (СР) должен соответствовать диапазону от 482 до 655 МПа. Кроме того, операция отжига заготовок фитинга должна проводиться в вакууме, с тем, чтобы максимальное содержание водорода не превышало 10 ppm

Независимо от схемы пластической деформации, наилучшие результаты для образования плотного контакта "металл-металл" обеспечивают следующие комбинации материалов для фитингов и труб:

- для титанового фитинга (ВТ1-0) использовать трубы из титанового сплава Ti-3Al-2.5V (AMS4944, AMS4945).

- для алюминиевого фитинга использовать трубы из алюминиевого сплава АД 33 по ГОСТ 4784-97, для фитинга из нержавеющей стали 07Х21Г7, ГОСТ 5632-72 (сталь 21-6-9, AMS5561) использовать трубы из следующих материалов: алюминиевый сплав АД33, ГОСТ 4784-97 (6061-Т6 $\mathrm{Al}$ ), или сталь 07Х21Г7, ГОСТ 5632-72 ( 21-6-9 SS, AMS 5561), или титановый сплав Тi-3Al-2.5V, или сталь 08 X18 Н10, ГОСТ 5949-75 (304 1/8HD SS)

Более подробная информация о сочетании материалов фитингов и труб для различных схем пластической деформации представлены в таблицах 1- 3 [8-12].

Табл. 1. Материалы для радиально сжатых соединений

\begin{tabular}{|c|c|c|c|}
\hline $\begin{array}{l}\text { Вид материала } \\
\text { фиттинга }\end{array}$ & $\begin{array}{l}\text { Материал } \\
\text { фиттинга* }\end{array}$ & Материал трубы* & $\begin{array}{l}\text { Максимальное } \\
\text { рабочее } \\
\text { давление, psi } \\
\text { (МПА)** }\end{array}$ \\
\hline \multirow{5}{*}{$\begin{array}{l}\text { Нержавеющая } \\
\text { сталь }\end{array}$} & $\begin{array}{ll}07 X 21 \Gamma 7, & \text { ГОСТ } \\
5632-72 & \end{array}$ & $\begin{array}{l}\text { 07Х21Г7, ГОСТ 5632-72 } \\
(21-6-9, \text { AMS5561) }\end{array}$ & \multirow{4}{*}{$3000(20,70)$} \\
\hline & \multirow[t]{3}{*}{$\begin{array}{l}(21-6-9, \\
\text { AMS5656) }\end{array}$} & $\begin{array}{l}08 \text { X18 H10, ГОСТ 5949-75 } \\
\text { (304 1/8HD, AMS5564) }\end{array}$ & \\
\hline & & $\begin{array}{l}\text { Титановый сплав } \\
\text { (Ti-3Al-2.5V, AMS4944) }\end{array}$ & \\
\hline & & $\begin{array}{l}\text { АД33, ГОСТ 4784-97 } \\
\text { (6061-Т6, АMS4083) }\end{array}$ & \\
\hline & $\begin{array}{l}\text { 03X17H14M3 } \\
\text { ГОСТ 5632-72 }\end{array}$ & $\begin{array}{l}08 \text { X18 H10, ГОСТ 5949-75 } \\
(304 \text { 1/8HD, AMS5564) }\end{array}$ & $3000(20,70)$ \\
\hline
\end{tabular}




\begin{tabular}{|c|c|c|c|}
\hline & \multirow[t]{2}{*}{ (316L, AMS5648) } & & \\
\hline & & $\begin{array}{l}\text { 08X18H12T, 08X18H10T, } \\
\text { ГОСТ 5632-72 } \\
(321, \text { AMS5556) }\end{array}$ & $3000(20,7)$ \\
\hline $\begin{array}{l}\text { Алюминиевый } \\
\text { сплав }\end{array}$ & $\begin{array}{l}\text { АД33, } \\
\text { ГОСТ 4784-97 } \\
\text { (6061-T6, overage) }\end{array}$ & $\begin{array}{l}\text { АД33, } \\
\text { ГОСТ 4784-97 } \\
(6061-T 6, \\
\text { AMS4083) }\end{array}$ & $1500(10,3)$ \\
\hline Титан & $\begin{array}{l}\text { Титан } \\
\text { (CP-Titanium, } \\
\text { AMS 4941) }\end{array}$ & $\begin{array}{l}\text { Титановый сплав } \\
\text { (Тi-3Al-2.5V, AMS4944) }\end{array}$ & $4000 \quad(27,6)$ \\
\hline
\end{tabular}

* в скобках приведена маркировка США

** Определяется в зависимости от наружного диаметра и толщины стенки трубы

Табл. 2. Материалы для аксиально обжатых MAF-соединений

\begin{tabular}{|c|c|c|c|}
\hline $\begin{array}{l}\text { Вид материала } \\
\text { фиттинга }\end{array}$ & $\begin{array}{l}\text { Материал } \\
\text { фиттинга* }\end{array}$ & Материал трубы* & $\begin{array}{l}\text { Максимальное } \\
\text { рабочее } \\
\text { давление, psi } \\
\text { (МПА) ** }\end{array}$ \\
\hline \multirow{4}{*}{$\begin{array}{l}\text { Нержавеющая } \\
\text { сталь }\end{array}$} & \multirow{4}{*}{$\begin{array}{l}07 X 21 \Gamma 7, \\
\text { ГОСТ 5632-72 } \\
(21-6-9, \\
\text { AMS5656) }\end{array}$} & $\begin{array}{l}\text { 07Х21Г7, ГОСТ 5632-72 } \\
(21-6-9, \text { AMS5561) }\end{array}$ & $4000(27,6)$ \\
\hline & & $\begin{array}{l}08 \text { X18 H10, ГОСТ 5949-75 } \\
\text { (304 1/8HD, AMS5564) }\end{array}$ & $3000(20,7)$ \\
\hline & & $\begin{array}{l}\text { Титановый сплав } \\
\text { (Тi-3Al-2.5V, AMS4944) }\end{array}$ & $5000(34,5)$ \\
\hline & & $\begin{array}{l}\text { АД33, ГОСТ 4784-97 } \\
(6061-\mathrm{T} 6, \text { AMS4083) }\end{array}$ & $1500(10,3)$ \\
\hline $\begin{array}{l}\text { Алюминиевый } \\
\text { сплав }\end{array}$ & $\begin{array}{l}\text { АД33, } \\
\text { ГОСТ 4784-97 } \\
\text { (6061-T6, overage) }\end{array}$ & $\begin{array}{l}\text { АД33, ГОСТ 4784-97 } \\
\text { (6061-Т6, AMS4083) }\end{array}$ & $1500(10,3)$ \\
\hline Титан & $\begin{array}{l}\text { Титановый сплав } \\
\text { (Ti-6Al-4V, AMS } \\
\text { 4928) }\end{array}$ & $\begin{array}{l}\text { Титановый сплав } \\
\text { (Ti-3Al-2.5V, AMS4944) }\end{array}$ & $4000(27,6)$ \\
\hline
\end{tabular}

* в скобках приведена маркировка США

** Определяется в зависимости от наружного диаметра и толщины стенки трубы 
Табл. 3. Материалы для радиально-аксиально сжатых соединений

\begin{tabular}{|c|c|c|c|}
\hline Вид материала & $\begin{array}{l}\text { Материал } \\
\text { фиттинга* }\end{array}$ & Материал трубы* & $\begin{array}{l}\text { Максимальное } \\
\text { рабочее } \\
\text { давление, psi } \\
\text { (МПА) ** }\end{array}$ \\
\hline \multirow{6}{*}{$\begin{array}{l}\text { Нержавеющая } \\
\text { сталь }\end{array}$} & $\begin{array}{l}\text { 07Х16Н4Д4Б, } \\
\text { ГОСТ 5632-72 } \\
(17 \quad-\quad 4 \mathrm{PH}, \\
\text { AMS5643) }\end{array}$ & $\begin{array}{l}\text { Титановый сплав } \\
\text { (Ti-3Al-2.5V, AMS4945) }\end{array}$ & $\begin{array}{r}2000-4000 \\
(13,8-27,6)\end{array}$ \\
\hline & $\begin{array}{l}07 \mathrm{X} 21 \Gamma 7, \quad \text { ГОСТ } \\
5632-72\end{array}$ & $\begin{array}{l}\text { 07X21Г7, ГОСТ 5632-72 } \\
(21-6-9, \text { AMS5561) }\end{array}$ & $3000(20,7)$ \\
\hline & \multirow{4}{*}{$\begin{array}{r}(21-6-9, \\
\text { AMS5656) }\end{array}$} & $\begin{array}{l}304 \text { 1/8HD } \\
\text { (AMS5564) }\end{array}$ & $\begin{array}{l}1500-3000 \\
(10,3-20,7)\end{array}$ \\
\hline & & $\begin{array}{l}\text { Титановый сплав } \\
\text { (Ti-3Al-2.5V, AMS4945) }\end{array}$ & $\begin{array}{l}500-5000 \\
(3,4-34,4)\end{array}$ \\
\hline & & $\begin{array}{l}\text { Титан (CP-Titanium, ASTM } \\
\text { В338) }\end{array}$ & $750 \quad(5,2)$ \\
\hline & & $\begin{array}{l}\text { АД33, ГОСТ 4784-97 } \\
(6061-\mathrm{T} 6, \text { AMS4083) }\end{array}$ & $\begin{array}{l}500-1500 \\
(3,4-10,3)\end{array}$ \\
\hline Титан & $\begin{array}{l}\text { Титановый сплав } \\
\text { (Ti-6Al-4V, AMS } \\
\text { 4928) }\end{array}$ & $\begin{array}{l}\text { Титановый сплав } \\
\text { (Ti-3Al-2.5V, AMS4945) }\end{array}$ & $3000(20,7)$ \\
\hline
\end{tabular}

* в скобках приведена маркировка США

** Определяется в зависимости от наружного диаметра и толщины стенки трубы

\section{Выводы}

1. Представлен анализ материалов и современных технологий производства неразъемных соединений методом холодной пластической деформации

2. Обсуждены теоретические основы формирования механических соединений и роли фактора упругого последствия.

3. Представлен анализ сочетаний материалов для контактирующих пар, используемых для формирования механических соединений, которые гарантируют высокую надежность гидравлических трубопроводов высокого давления (27,6-34,5 МПа).

\section{Библиографический список}

1. ASTM F1387-99 Standard Specification for Performance of Piping and Tubing Mechanically Attached Fittings. 2005.

2. Lokring technology. - URL: http//www.sabtek.co.uk (19.10.2017).

3. Products. - URL: http//www.dmcusa.com (19.10.2017).

4. SAE AS4459, Fittings, Tube, Fluid System Aerospace Standard. Externally Swaged. 
5. Zhen L., Cui Y. X. \& Shao W. Z. Materials Science and Engineering / L. Zhen, Y. X. Cui, W. Z. Shao. - 2002. - vol. 336, - Iss. 1-2, pp.135-142.

6. Радкевич M. M. Технология упрочняющей программной механико-термической обработки / М. М. Радкевич. - СПб: Издательство Политехнического университета, 2011. - 263 с.

7. ASM Handbook, vol. 20, Materials Selection and Design. 293 p.

8. ASTM Designation: A370-07a Standard Test Methods and Definition for Mechanical Testing of Steel Products

9. ASTM Designation: E8-04 Standard Test Methods for Tension Testing of Metallic Materials

10. ASM International. Metals Handbook.

11. Сорокин В. Г. Марочник сталей и сплавов / В. Г. Сорокин, А. В. Волосникова, С. А. Вяткин и др; под общ. ред. В. Г. Сорокина. М.: Машиностроение, 1989. - 640 с.

12. Смирнягин А. П. Промышленные цветные металлы и сплавы. Справочник / А. П. Смирнягин. - М.: Издательство "Металлургия". - C. 1-974.

\section{References}

1. ASTM F1387-99 Standard Specification for Performance of Piping and Tubing Mechanically Attached Fittings. 2005.

2. Lokring technology. - URL: http//www.sabtek.co.uk (19/10/2017).

3. Products. - URL: http//www.dmcusa.com (19/10/2017).

4. SAE AS4459, Fittings, Tube, Fluid System Aerospace Standard. Externally Swaged.

5. Zhen L., Cui Y. X. \& Shao W. Z. Materials Science and Engineering, vol. 336, Issues 1-2, 2002, p.135-142.

6. Radkevich M. M. Tekhnologiya uprochnyayushchej programmnoj mekhaniko-termicheskoj obrabotki [Technology of hardening programmed mechanical heat treatment]. St. Petersburg, 2011. 263 p. (In Russian)

7. ASM Handbook, vol. 20, Materials Selection and Design. 293 p.

8. ASTM Designation: A370-07a Standard Test Methods and Definition for Mechanical Testing of Steel Products

9. ASTM Designation: E8-04 Standard Test Methods for Tension Testing of Metallic Materials

10. ASM International. Metals Handbook.

11. Sorokin V. G., Volosnikova A. V. \& Vyatkin S. A. Marochnik stalej $i$ splavov [Grades of steels and alloys of steels and alloys]. Moscow, 1989. 640 p. (In Russian)

12. Promyshlennye cvetnye metally $i$ splavy. Spravochnik [Industrial nonferrous metals and alloys. Reference]. Moscow, 1974. (In Russian) 


\section{Сведения об авторах:}

КОГАН Яков Давидович, доктор технических наук, AR Materials Solution, Inc.

E-mail: yakovkogan@sbcglobal.net

БОГДАНОВА Наталья Васильевна, кандидат технических наук, доцент кафедры ТМиМ, Государственного университета морского и речного флота имени адмирала С. О. Макарова E-mail: nabo146@mail.ru

\section{Information of author:}

Yakov D. KOGAN, Doctor of Technical Sciences, AR Materials Solution, Inc.

E-mail: yakovkogan@sbcglobal.net

Natal'ya V. BOGDANOVA, Candidate of Technical Sciences, Associate Professor of TMM, Admiral Makarov State University of Maritime and Inland Shipping

E-mail: nabo146@mail.ru

(С КОГАН Я. Д., БОГДАНОВА Н. В., 2017 